\title{
Tradução e cientificidade
}

Claudemir Roque Tossato ${ }^{1}$

\begin{abstract}
Resumo: Pretende-se neste artigo apresentar algumas possibilidades de tradução de três conceitos utilizados por J. Kepler na elaboração de suas leis dos movimentos planetários, a saber, commoditates, harmonia e moles. $\mathrm{O}$ artigo ainda trata da importância de conjugar a tradução dos conceitos dentro do escopo teórico empregado por Kepler quando do processo de elaboração das suas leis. Para tanto, as traduções propostas aos três conceitos são cotejadas com as utilizadas nas traduções inglesa, francesa e espanhola.
\end{abstract}

Palavras-chave: Kepler, leis, tradução, astronomia, cosmologia.

\section{Introdução}

Johannes Kepler (1571-1630) ocupa um lugar central no desenvolvimento da ciência moderna. O âmbito de seus trabalhos é extremamente amplo, tratando da matemática, da óptica e, especialmente, da astronomia e da cosmologia. Em relação a essas últimas, Kepler elaborou as denominadas três leis dos movimentos dos planetas, unificando a astronomia de posição com a cosmologia teórica. Estas leis trouxeram, no processo de suas elaborações, uma drástica modificação na noção metodológica de "hipóteses astronômicas" que, em termos gerais, deixaram de ser meras descrições instrumentais sobre os movimentos dos planetas - em que eram voltadas para somente descrever com mais competência os posicionamentos dos planetas - e passam a representar a realidade dos acontecimentos supralunares. $\mathrm{Ou}$ seja, metodologicamente, Kepler defende uma postura realista em astronomia e cosmologia. Para obter essas leis através desta ruptura metodológica, Kepler entendeu a astronomia e a cosmologia como ciências únicas, tratando a questão dos movimentos dos planetas a partir da admissão de que tais movimentos apresentam regularidades expressas matematicamente pelo fato de haver uma força central exercida pelo Sol nos planetas. Em outras palavras, as regularidades matemáticas expressas pelas três leis dos movimentos dos planetas ocorrem pela explicação causal de que o Sol exerce nos planetas uma força que, juntamente com a inércia natural dos planetas, os levam a esses comportamentos regulares ${ }^{2}$.

1 Professor adjunto da Universidade Federal de São Paulo. Este artigo foi elaborado a partir de uma conferência ministrada no campus Guarulhos em 18 nov. 2019.

2 Para uma ótima compreensão do processo de elaboração das leis de Kepler, algo que não será possível discutir neste texto, conferir KOYRÉ, A. La révolution astronomique. Paris: Hermann, 1961, uma obra clássica sobre Kepler e a astronomia dos séculos XVI 


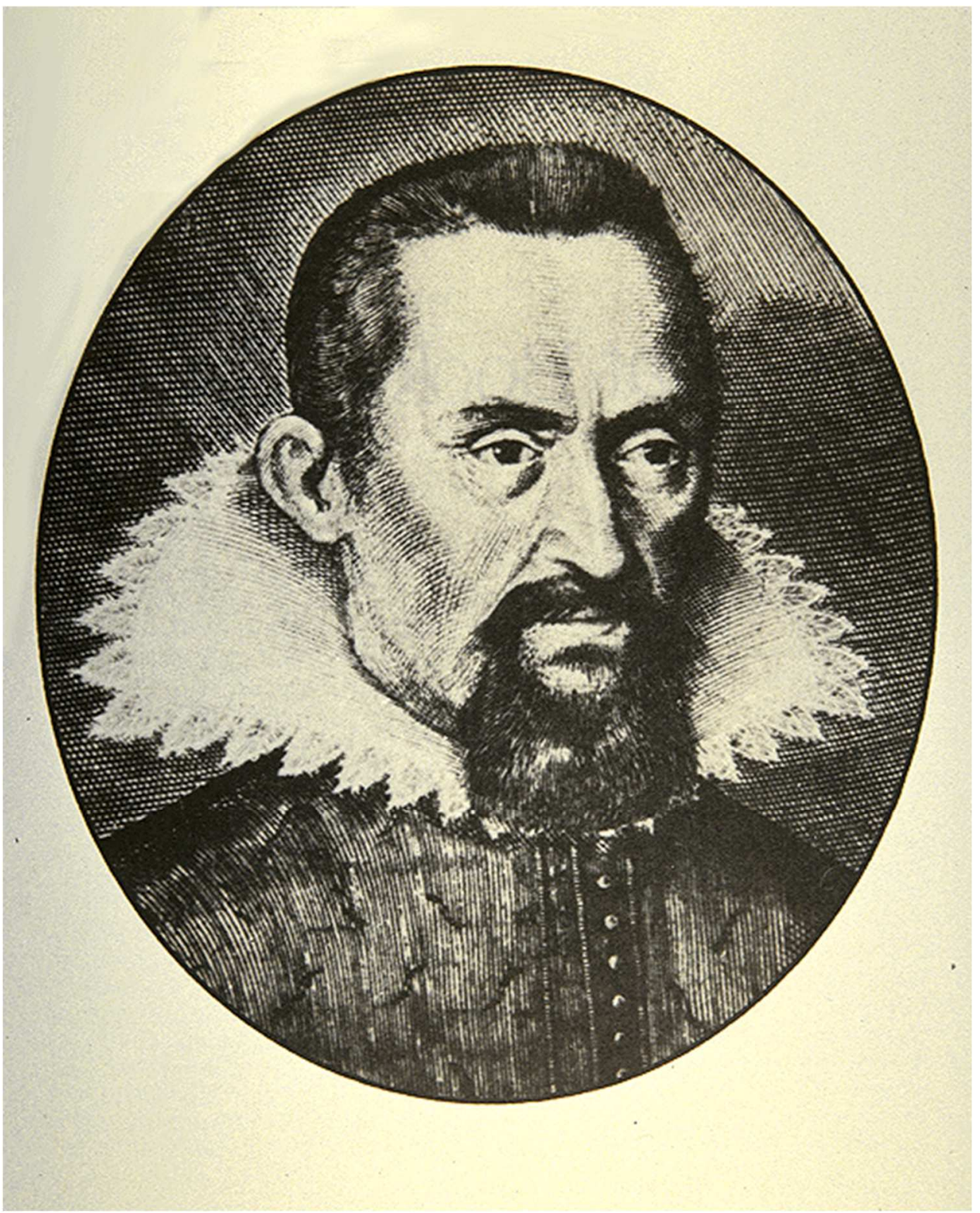

Figura 1 - Johannes Kepler (1571-1630) foi o principal astrônomo do século XVII. Sua principal contribuição foi a elaboração das três leis dos movimentos planetários: a lei da forma elíptica, a lei das áreas e a lei harmônica.

Para chegar a esses resultados, Kepler elaborou conceitos, e é neste ponto que desejo elaborar uma pequena discussão sobre a tradução de conceitos. Assim, o objetivo deste texto é discutir as possibilidades de tradução de três conceitos utilizados por Kepler quando de sua elaboração das leis dos movimentos planetário,

e XVII que, apesar de antiga, ainda é considerada uma leitura indispensável. Mais recente é STEPHENSON, B. Kepler's Physical Astronomy. New York: Springer Verlag, 1987, que reconstrói com muita competência os procedimentos keplerianos para a obtenção das les dos movimentos dos planetas. A principal biografia de Kepler continua a ser a de CASPAR, M. Kepler. New York: Dover Publications, 1959. Em português, tem-se a de MOURÃO, R. R. Kepler, a descoberta das leis do movimento planetário. Rio de Janeiro: Odysseus, 2003. 
a saber, commoditates, harmonia e moles. A minha intenção é explorar os significados atribuídos pelas traduções inglesa, francesa e espanhola a esses termos e investigar que tipo de tradução pode ser atribuída tendo em conta não somente o significado, as acepções, desses termos, mas como eles se inserem no conjunto da obra astronômica e cosmológica de J. Kepler. A tradução desses termos utilizados por Kepler traz a possibilidade de compreensão da sua maneira de entender a astronomia e a cosmologia. Contudo, entendo ainda que, quando se decide pela tradução de um termo, também está em jogo a admissão de uma interpretação da obra do cientista, no caso, da obra de Kepler. A discussão sobre as possibilidades de tradução desses três termos não exaure, obviamente, o conjunto dos termos keplerianos utilizados em astronomia e cosmologia, mas serve, apenas, como uma pequena ilustração das possibilidades de tradução de conceitos.

\section{Primeiro termo: commoditates}

Em 1596, Kepler publica a sua primeira obra astronômica, o Mysterium cosmographicum. Esta obra não apenas lançou o nome de Kepler nos meios científicos de sua época, sendo bem recebida por alguns e nem tanto, por outros, como lança a base para o processo de elaboração de suas três leis dos movimentos planetários, que serão obtidas subsequentemente, na Astronomia nova, de 1609, na qual estão as duas primeiras (a lei da órbita elíptica e a lei das áreas) e na Harmonia do mundo, de 1618 (que contém a terceira lei, a lei harmônica). Essa base é eminentemente metafísica, a saber, a de que o universo criado por Deus é uma estrutura geométrica que explica por que o universo contém seis planetas (Mercúrio, Vênus, Terra, Marte, Júpiter e Saturno), estando o Sol ao centro e o universo todo contido na esfera das estrelas fixas, isto é, Kepler adota, sem mudanças, as hipóteses de Copérnico.

O modelo representativo da estrutura geométrica do universo desenvolvido por Kepler é conhecido por modelo dos "sólidos perfeitos" ou também chamado de "taça cósmica". Sua explicação é dada, segundo Kepler, da seguinte maneira:

A Terra é o círculo que é a medida de tudo. Circunscreve a ela um dodecaedro; o círculo compreendido será Marte. Circunscreve a Marte um tetraedro; o círculo que o compreende será Júpiter. Circunscreve a Júpiter um cubo; o círculo que o compreende será Saturno. Então, inscreve um icosaedro à Terra; o círculo inscrito neste será Vênus. Inscreve em Vênus um octaedro; o círculo inscrito nele será Mercúrio. Tens a razão do número dos planetas ${ }^{3}$.

3 KEPLER, J. Mysterium cosmographicum. In: CASPAR. M. \& VON DICK, W. (Ed.). Gesammelte Werke, v. 1. Munich: C. H. Beck'sche Verlagsbuchhandlung, 1938, p. 13. 


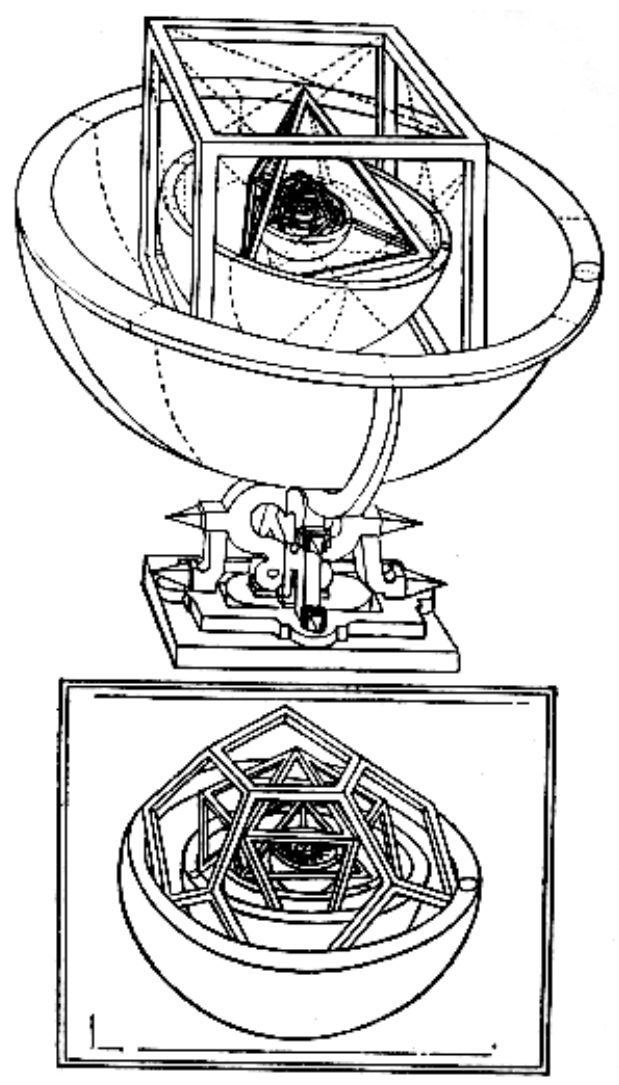

Figura 2 - O modelo planetário dos sólidos perfeitos. Nessa taça cósmica, Kepler pretendia demonstrar a razão por que Deus criou um universo com seis planetas e as proporções que existem entre eles. Para Kepler, as razões de Deus foram geométricas.
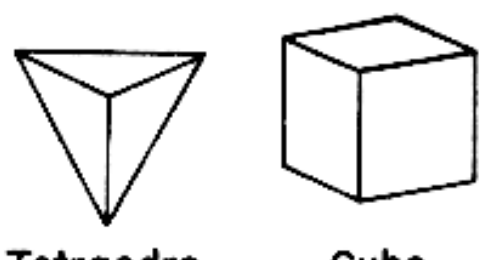

Cubo

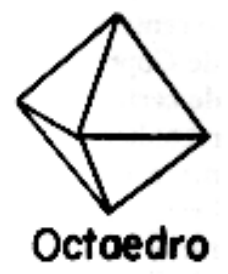<smiles>C1CC2CC3CC4CC5CC1CC5C(C2)(C3)C4</smiles><smiles>C12C3C4C5C6C(C5C3C16)C24</smiles>

Dodecaedro

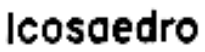

Figura 3 - Os cinco sólidos perfeitos conhecidos desde a época de Platão. Em cada uma dessas figuras, todas as suas faces e ângulos são iguais. 
Em tal modelo, Kepler inscreve e circunscreve os cinco sólidos perfeitos ${ }^{4} \mathrm{com}$ os seis planetas conhecidos, de maneira que, partindo do planeta mais próximo da esfera das estrelas fixas, temos:

\author{
Cubo \\ Esfera de Júpiter \\ Tetraedro \\ Esfera de Marte \\ Dodecaedro \\ Esfera da Terra \\ Icosaedro \\ Esfera de Vênus \\ Octaedro \\ Esfera de Mercúrio \\ Sol
}

Figura 4. Aqui percebe-se a intercalação entre os planetas e os sólidos. Estando o Sol no centro, tem-se em seguida a esfera de Mercúrio e, em seguida, o octaedro e, assim por diante.

Com tal modelo, Kepler pretendia explicar por que existem apenas seis planetas e a razão das distâncias, isto é, descrever geometricamente a estrutura do universo conhecido de sua época:

É meu propósito, leitor, demonstrar, com este pequeno livro, porque o Ótimo e Criador máximo utilizou, na criação deste mundo móvel e na disposição dos céus, aqueles cinco corpos regulares considerados, desde Pitágoras e Platão até nós, os mais frequentemente celebrados a se aplicar à Natureza a quantidade, as proporções e as razões dos movimentos ${ }^{5}$.

Como foi dito, Kepler adota as hipóteses copernicanas de centralidade do Sol e movimentos da Terra nesse seu modelo. Como é sabido, na época de Kepler, o modelo adotado era o geocêntrico, no qual o centro é a Terra e o Sol, os planetas e a esfera das estrelas fixas giram ao seu redor, modelo este que teve Ptolomeu como seu maior representante. É nesta disputa que surge a utilização do termo commoditates.

4 Sólidos perfeitos são os únicos polígonos regulares e congruentes, isto é, figuras geométricas sólidas nas quais todas as faces bidimensionais são idênticas em figura e ângulos. Todas idênticas em forma, tamanho e ângulos entre si. Esses sólidos eram conhecidos pelos gregos antigos, sendo dada a demonstração geométrica de que existem apenas esses sólidos perfeitos nos Elementos de Euclides, livro XIII, proposições 13-17.

5 KEPLER, J. Mysterium cosmographicum. In: CASPAR. M. \& VON DICK, W. (Ed.). Gesammelte Werke, v. 1. Munich: C. H. Beck'sche Verlagsbuchhandlung, 1938, p. 9. 
O termo commoditates é utilizado por Kepler em sua obra Mysterium cosmographicum e sua utilização merece uma análise detida. Acredito que a sua conotação pode indicar o modo pelo qual Kepler estava considerando o sistema copernicano que, de certa forma, já indicava a necessidade de uma renovação metodológica para o tratamento astronômico e cosmológico no final do século XVI. Defendo que a tradução desse termo conduz a caminhos distintos para a compreensão da maneira kepleriana de entender a astronomia e a cosmologia. Algo que passarei a discorrer brevemente.

O texto original em latim do Mysterium cosmographicum é muito rico no que concerne aos conceitos utilizados por Kepler, seja na edição de 1595, antes da descoberta das leis, seja na edição de 1621, com as notas adicionadas por Kepler, após ter descoberto as suas leis.

Utilizo o texto em latim do Mysterium cosmographicum, o mesmo que foi utilizado pelas traduções inglesa, francesa e espanhola. O texto em latim encontra-se no volume 1 das obras completas de Kepler editadas por M. Caspar e W. van Dick (a segunda edição, de 1621, que contém as notas acrescentadas à edição original, está no volume 8 das mesmas obras completas). Cotejarei o texto latino com as seguintes traduções: o texto em inglês, de 1981, traduzido por A. M. Ducan, feita pela Abaris Books, New York); francesa (Le secret du monde, de 1984, traduzido por Alain Segonds, a partir de um ensaio inicial de Louis-Paul Cousin, da Gallimard, Paris) e espanhola (El secreto del universo, de 1992, traduzido por Eloy Rada García, da Alianza Editorial, Madrid).

O que defendo é que os conceitos empregados por Kepler devem ser traduzidos de um modo que sejam condizentes com os significados que ele, Kepler, pretendeu dar. Neste sentido, as traduções francesa, espanhola e inglesa parecem confundir os significados originais de Kepler em relação ao termo commoditates. Vejamos um exemplo. No prefácio à obra, Kepler escreve em latim:

Atque in hunc usum partim ex ore Mästlin, parte meo marte, quas Copernicus in mathesi prae Ptolomeu habet commoditates, paulatim collegi'.

Que traduzo como:

E coligi, para este uso, pouco a pouco, em parte da boca de Mästlin, em parte de meus recursos, as justas proporções matemáticas que Copérnico apresenta sobre Ptolomeu.

6 KEPLER, J. Mysterium cosmographicum. In: CASPAR. M. \& VON DICK, W. (Ed.). Gesammelte Werke, v. 1. Munich: C. H. Beck'sche Verlagsbuchhandlung, 1938, p. 9. 
Sublinhei "as justas proporções matemáticas" para comparar com as traduções francesa, espanhola e inglesa. Inicialmente, a inglesa:

And for this purpose I collected together little by little, partly from the works of Maestlin, partly by my own efforts, the advantages which Copernicus has mathematically over Ptolomy ${ }^{7}$.

\section{A francesa:}

Et dans ce but, je me mis à rassembler peu à peu soit à partir de l'enseignement de Mastlin soit par mes propres forces, les avantages que Copernic présent, du point de vue mathématique, par rapport à Ptolémée ${ }^{8}$.

Finalmente, a espanhola:

Con este propósito poco a poco reuní, em parte de las ensenanzas de Maestlin y em parte por mi proprio esfuerzo, las ventajas de orden matemático de Copérnico sobre Ptolomeu?.

Ou seja, as três traduções interpretam commoditates como vantagem, enquanto utilizo justa proporção. O que é preciso, penso, é relacionar o uso de "vantagens matemáticas" ou "justas proporções matemáticas" com a maneira que Kepler concebeu o copernicanismo em 1596. Acredito que não é somente uma questão de preferência: "vantagem matemática" ou "justas proporções" apontam para interpretações distintas sobre o método. Algo sobre o que passarei a discorrer.

A questão pode ser posta da seguinte maneira: se a escolha for por "vantagens matemáticas", a compreensão acerca do entendimento de Kepler sobre o copernicanismo recairá em uma leitura instrumentalista por parte dele. Se utilizamos, por outro lado, "justas proporções matemáticas" ou da "simetria", estaremos no âmbito do "realismo" cosmológico.

Inicialmente, deve-se dizer que o termo commmoditates é o acusativo plural do nominativo commoditas, que significa: 1. justa proporção, simetria, proporção; 2 . comodidade, oportunidade, ocasião, favorável; 3. vantagem, benevolência etc. Bem, as traduções inglesa, francesa e espanhola traduzem o termo na terceira acepção, muito longe, creio, do que, talvez, seja o sentido empregado por Kepler, porque, na primeira acepção, "justa proporção", "simetria" e "proporção" estão mais próximos do sentido de "justas proporções matemáticas" do que "vantagens matemáticas". A

7 KEPLER, J. Mysterium cosmographicum. Trad. A. M. Ducan. New York: Abaris Books, 1981, p. 63.

8 KEPLER, J. Le secret du monde. Trad. e notas de Alain Segonds. Paris: Gallimard, 1984, p. 31-32.

9 KEPLER, J. El secreto del universo. Trad. Eloy Rada García. Madrid: Alianza Editorial, 1992a, p. 66. 
questão não é meramente, penso, de semelhança dos termos, mas da postura de Kepler frente ao copernicanismo em relação ao geocentrismo em 1595. Se utilizarmos "vantagem", como fazem as traduções inglesa, francesa e espanhola, poderemos interpretar que o copernicanismo é vantajoso matematicamente porque é mais simples, utiliza menos expedientes matemáticos do que os modelos de Ptolomeu etc., ou seja, tem um caráter matemático mais vantajoso e, portanto, superior do ponto de vista matemático, de maneira a dar suporte a uma leitura instrumentalista, na qual não importa tratar a questão sobre a realidade dos fenômenos, mas, somente, obter vantagens, superioridades, nos cálculos. Porém, isto não é verdadeiro, pois o copernicanismo original não era mais vantajoso (superior) que os modelos ptolomaicos; eles eram equivalentes tanto observacional quanto matematicamente ${ }^{10}$; a superioridade que Copérnico tem sobre Ptolomeu está no caráter cosmológico e físico ${ }^{11}$ e não no caráter matemático.

É importante ter em vista que o copernicanismo do final do século XVI e início do XVII não é o copernicanismo como entendemos hoje, isto é, o copernicanismo que engloba os trabalhos de Kepler, Galileu e Newton. Copérnico elaborou as hipóteses de centralidade do Sol e movimentos da Terra, mas essas, originariamente, não tinham, obviamente, a força que tiveram subsequentemente. Assim, a questão que coloco é: o que o copernicanismo permitiu a Kepler? Entendo que ele permitiu uma nova disposição dos corpos celestes, admitindo a noção de "sistema", isto é, a relação entre as partes desse sistema (cada planeta, o Sol etc.) com o todo. Copérnico já adianta essa noção quando compara os modelos ptolomaicos com a figura de um "monstro", em que cada parte, um planeta, o Sol etc. não tem relação com o todo ${ }^{12}$. Somente colocando o Sol ao centro e dotando a Terra de movimentos é que se pode integrar as partes com o todo. Assim, não está em jogo apenas uma nova disposição matemática, mas uma nova disposição cosmológica que permite, isto sim, aplicar novas abordagens matemáticas. O próprio Kepler dá esta indicação, quando escreve logo no início do Mysterium cosmographicum, sobre as propostas copernicanas:

Sobre esse assunto, então, não fiquei prevenido por qualquer impedimento religioso sobre a consistência do que Copérnico diz em sua teoria. Minha confiabilidade em Copérnico foi estabelecida primeiramente pela magnífica concordância de tudo que é observado nos céus com a sua teoria, visto que ele não apenas derivou os movimentos passados os quais foram obtidos desde as

10 HANSON, N. Constelaciones y conjeturas. Madrid: Alianza Universidad, 1985, p. 223261.

11 COSTABEL, P. "Kepler and the copernican model". Vistas in astronomy, 18, p. 217-222, 1975.

12 COPÉRNICO, N. As revoluções dos orbes celestes. Lisboa: Fundação Calouste Gulbenkian, 1984, p. 5-11. 
mais remotas observações da antiguidade, mas também prediz movimentos futuros, não de fato com uma grande certeza, mas com mais certeza que Ptolomeu, Alfonso e o restante. Entretanto, o que é mais importante do que tudo isso é que, para as coisas que os outros deram como milagres, apenas Copérnico magnificamente deu razões, e removeu as causas dos milagres, as quais não são causas conhecidas ${ }^{13}$.

As razões aludidas por Kepler são, penso, a nova disposição cosmológica dada pelo copernicanismo nascente; "justas proporções", tal como defendo para a tradução de commoditates, é fundamentada na noção de sistema, em que posicionar o Sol no centro de movimentos permite encontrar as justas proporções entre as distâncias planetárias, tal como são expressas pelas suas leis dos movimentos dos planetas.

Assim, se optarmos por "justas proporções", o sentido nos remete não para uma superioridade matemática do copernicanismo em relação ao geocentrismo de Ptolomeu, mas de razões, proporções no campo cosmológico. O próprio termo "justa proporção" também pode ser substituído por "simetria", como está na primeira acepção do termo, algo que também é possível justificar; contudo, de maneira alguma vejo possibilidade da utilização de "vantagem" como é escrito nas edições arroladas.

\section{Segundo termo: harmonia}

Outro termo problemático é o de "harmonia". As edições francesa e espanhola utilizam-no de formas distintas e que, talvez, não correspondam ao significado do conceito. Vejamos uma passagem, entre muitas outras, que o termo harmonia aparece. No capítulo 12 do Mysterium cosmographicum, temos no original latino:

Ut autem singulae harmoniae singulis corporibus accomodentur, no ita in promptu est ${ }^{14}$.

Que traduzimos por:

No entanto, a acomodação das harmonias singulares nos corpos singulares não é fácil.

13 KEPLER, J. Mysterium cosmographicum. In: CASPAR. M. \& VON DICK, W. (Ed.). Gesammelte Werke, v. 1. Munich: C. H. Beck'sche Verlagsbuchhandlung, 1938, p. 14-15, itálicos meus.

14 KEPLER, J. Mysterium cosmographicum. In: CASPAR. M. \& VON DICK, W. (Ed.). Gesammelte Werke, v. 1. Munich: C. H. Beck'sche Verlagsbuchhandlung, 1938, p. 41. 
A edição francesa traduz por "Mais faire correspondre à chaque corps un accord, cela n'est pas aussi facile" 15 , isto é, utiliza harmonia por "um acordo"; a espanhola traduz por "Pero para que cada consonancia se acomode a cada sólido, la cosa no es tan inmediata"16, aqui a interpretação estabelece harmonia como "consonância"; a inglesa, por sua vez, mantém um respeito maior ao termo, pois traduz a passagem por "However, the fitting of the individual harmonies to the individual solids is less readily achieved"17, traduzindo por "harmonia".

O sentido de harmoniae no texto latino provém do termo harmonia, nominativo que significa: 1. harmonia, proporção entre as partes dum todo, simetria, ordem; 2 . melodia, sucessão, melodia de sons. Ora, interpretar harmoniae por "acordo" ou "consonância" não é respeitar plenamente o significado de relação entre as partes com o todo.

Contudo, o fundamental é que o conceito de harmonia de Kepler é muito importante para a compreensão da sua astronomia, o que implica um grande cuidado e precisão na sua utilização. Para compreendermos o conceito de harmonia de Kepler é preciso investigá-lo na Harmonia do mundo, especialmente o livro IV, no qual Kepler distingue harmonia absoluta de harmonia individual, o que as leituras das traduções francesa e espanhola parecem não explorar suficientemente.

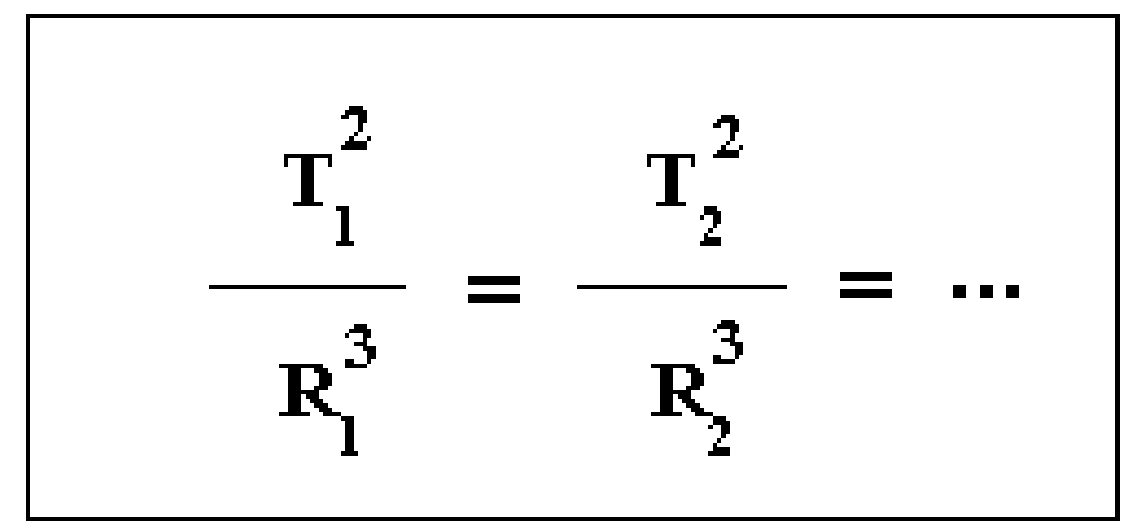

Figura 5 - A terceira lei de Kepler, denominada "lei harmônica". Para dois planetas quaisquer, o cubo de suas distâncias ao Sol são proporcionais ao quadrado de seus tempos de percurso ao redor do Sol.

15 KEPLER, J. Le secret du monde. Trad. e notas de Alain Segonds. Paris: Gallimard, 1984, p. 103.

16 KEPLER, J. El secreto del universo. Trad. Eloy Rada García. Madrid: Alianza Editorial, 1992a, p. 134.

17 KEPLER, J. Mysterium cosmographicum. Trad. A. M. Ducan. New York: Abaris Books, 1981, p. 133. 
A Harmonia do mundo, de 1618, é a obra de Kepler que apresenta a terceira lei dos movimentos planetários, chamada de "lei harmônica", a qual afirma que para quaisquer dois planetas, os cubos de suas distâncias ao Sol são proporcionais aos quadrados de seus períodos (tempos). A obra é composta por cinco partes e Kepler trata da harmonia na quarta parte da obra.

Kepler apresenta na quarta parte da Harmonia do mundo dois pontos fundamentais para o seu conceito de harmonia. Em primeiro lugar, a admissão de que a estrutura do mundo celeste é harmônica, isto é, existe uma estrutura subjacente aos fenômenos celestes observados (seus aspectos físicos e observáveis) que corresponde à possibilidade de elaborarmos leis, ou seja, uma estrutura matemática que garante a necessidade para a aplicação das leis. Em segundo lugar, para Kepler, o sujeito que conhece tem condições de expressar essa estrutura harmônica. Para tanto, será fundamental a divisão entre harmonia sensível e a absoluta. Como ele escreve:

[...] uma coisa é a harmonia sensível ou análoga a ela, outra é a harmonia secreta e pura, unida às coisas sensíveis [Aliud enim est Harmonia sensilis, vel ei analoga, aliud Harmonia secreta et pura a rebus sensilibusi]; aquelas são numerosas tanto pela maneira de ser dos objetos, pelas suas diferenças, quanto pela razão de ser do indivíduo; mas a harmonia pura encontra-se afastada das coisas sensíveis e é única e a mesma de qualquer modo que seja vista ${ }^{18}$.

Por um lado, existe o sujeito que conhece os objetos, que, conhecendo-os pelos sentidos, nota-os de acordo com as informações postas pela visão, audição etc. Por outro lado, existe o objeto com suas características sensíveis próprias e, além disto, a sua relação com outros objetos. Assim, por exemplo, podemos observar uma pintura representando objetos, como pessoas, casas, árvores etc. e termos uma impressão que nos dá a sugestão de harmonia, pois notamos que a pessoa representada na pintura mantém uma relação de proporcionalidade tanto com a casa quanto com a árvore representadas e, do mesmo modo, a casa com a árvore. Mas esta é uma harmonia que carrega em si todas as "imperfeições" que estão presentes quando o sujeito observa um objeto. Por outro lado, a harmonia secreta ou pura é sempre a mesma, pois ela não está sujeita às imprecisões do sensível.

A harmonia pura ou secreta é, pode-se dizer, uma estrutura que não é percebida sensivelmente, mas a sua existência permite a afirmação de que o mundo é regular e harmônico. Em outros termos, a harmonia pura é uma estrutura que está subjacente aos fenômenos. Sua ordem é metafísica.

18 KEPLER, J. Harmonice mundi. In: CASPAR. M. \& VON DICK, W. (Ed.). Gesammelte Werke, v. 6. Munich: C. H. Beck'sche Verlagsbuchhandlung, 1940, p. 211. 
O problema de Kepler foi garantir que as informações postas pela harmonia sensível sejam subsumidas à harmonia absoluta, ou, o que penso ser o mesmo, passar da harmonia subjetiva para a estrutura da harmonia objetiva. Esta passagem permite, no quadro kepleriano de estrutura harmônica do mundo, obter leis, isto é, representações descritivas das regularidades quando os dados empíricos são englobados na estrutura da harmonia objetiva. O que temos com isto é o pitagorismo kepleriano, ou seja, a crença de Kepler de que o mundo foi criado de uma maneira harmônica. A harmonia secreta é a harmonia universal que representa a verdadeira realidade do mundo celeste.

E como, pelo que foi dito, a estrutura harmônica pura não é sensível, não podemos percebê-la pelos sentidos; assim, ela deve ser tratada pelo pensamento, pois:

[...] toda relação não se apresenta sem o pensamento [...]. Portanto, o que é verdadeiro para os objetos da relação deve ser suposto mais especialmente para os objetos da harmonia, que consiste nas proporções e nas contagens das partes iguais da quantidade [...]. Certamente, a Harmonia é uma coisa única, os termos sensíveis, fora dela, ou longe da alma, não são coisas unas e não podem ser unidos, a não ser no íntimo da alma ${ }^{19}$.

E a linguagem que conjuga a harmonia sensível com a pura é a linguagem matemática, pois é pelo pensamento que tratamos das entidades geométricas e numéricas, como círculos, retas, arcos e números. É a estrutura real e harmônica do espaço que é compreendida pelo pensamento, onde está localizada a fonte de percepção da harmonia pura. É ela que organiza as entidades matemáticas que são, por exemplo, desenhadas ou representadas sensivelmente. A harmonia arquetípica, componente da harmonia pura, é a responsável por dar essa inteligibilidade ao mundo:

[...] Com efeito, existe uma diferença muito clara entre a harmonia pura e a harmonia sensível ou concreta, porque na pura os termos existem a partir dos gêneros matemáticos do círculo e do arco formados por um modo determinado [...]; nas harmonias sensíveis, não existe necessariamente esta formação espacial; com efeito, elas podem ser ou linhas retas ou quantidades sensíveis formadas a partir de exemplos fiéis de sua harmonia arquetípica [...]. Mas a harmonia arquetípica não necessita de nada, porque os termos estão presentes na alma, nascidos com ela, e é a mais forte característica da alma e, portanto, a própria alma; eles não são a imagem do seu paradigma, mas são os próprios paradigmas $^{20}$.

19 KEPLER, J. Harmonice mundi. In: CASPAR. M. \& VON DICK, W. (Ed.). Gesammelte Werke, v. 6. Munich: C. H. Beck'sche Verlagsbuchhandlung, 1940, p. 212.

20 KEPLER, J. Harmonice mundi. In: CASPAR. M. \& VON DICK, W. (Ed.). Gesammelte Werke, v. 6. Munich: C. H. Beck'sche Verlagsbuchhandlung, 1940, p. 216-217. 
Esse processo pode ser esquematizado como abaixo:

As coisas do mundo
geram informações $\sqrt[\begin{array}{c}\text { Faculdades dos sentidos } \\ \text { captam essas informações } \\ \text { (harmonia sensível, confusa) }\end{array}]{\begin{array}{c}\text { Faculdade superior (mente) } \\ \text { transforma em linguagem } \\ \text { própria (harmonia absoluta) }\end{array}}$

Portanto, traduzir harmonia por "acordo", como a tradução francesa, ou "consonância", como a espanhola, não representa, penso, a intenção kepleriana quando de suas abordagens na utilização de harmoniae. A harmonia kepleriana não representa acordo ou consonância, pois estes são termos que não expressam toda a importância dada por Kepler à harmonia.

\section{Terceiro termo: moles}

Moles é um termo utilizado por Kepler na introdução à Astronomia nova. Esta é a principal obra de Kepler. Nela, estão contidas as duas primeiras leis dos movimentos dos planetas. A primeira, que afirma que os planetas percorrem movimentos elípticos em torno do Sol e a segunda, que determina que os planetas percorrem, em seus movimentos elípticos em torno do Sol, áreas iguais em tempos iguais.

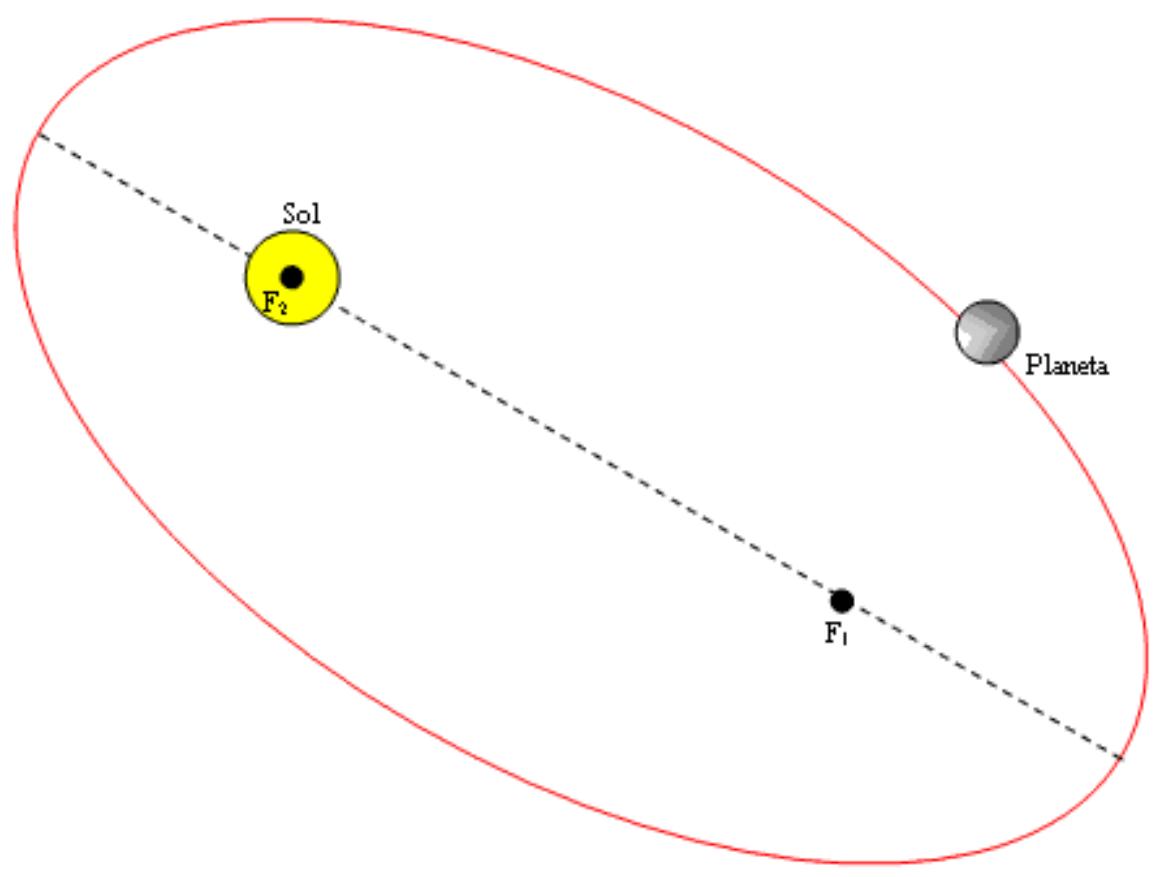

Figura 6 - Primeira lei da Kepler. A lei da órbita elíptica A forma das órbitas é elíptica e não, circular e uniforme. O Sol está em um dos focos da elipse enquanto o planeta percorre movimento elíptico ao seu redor. 


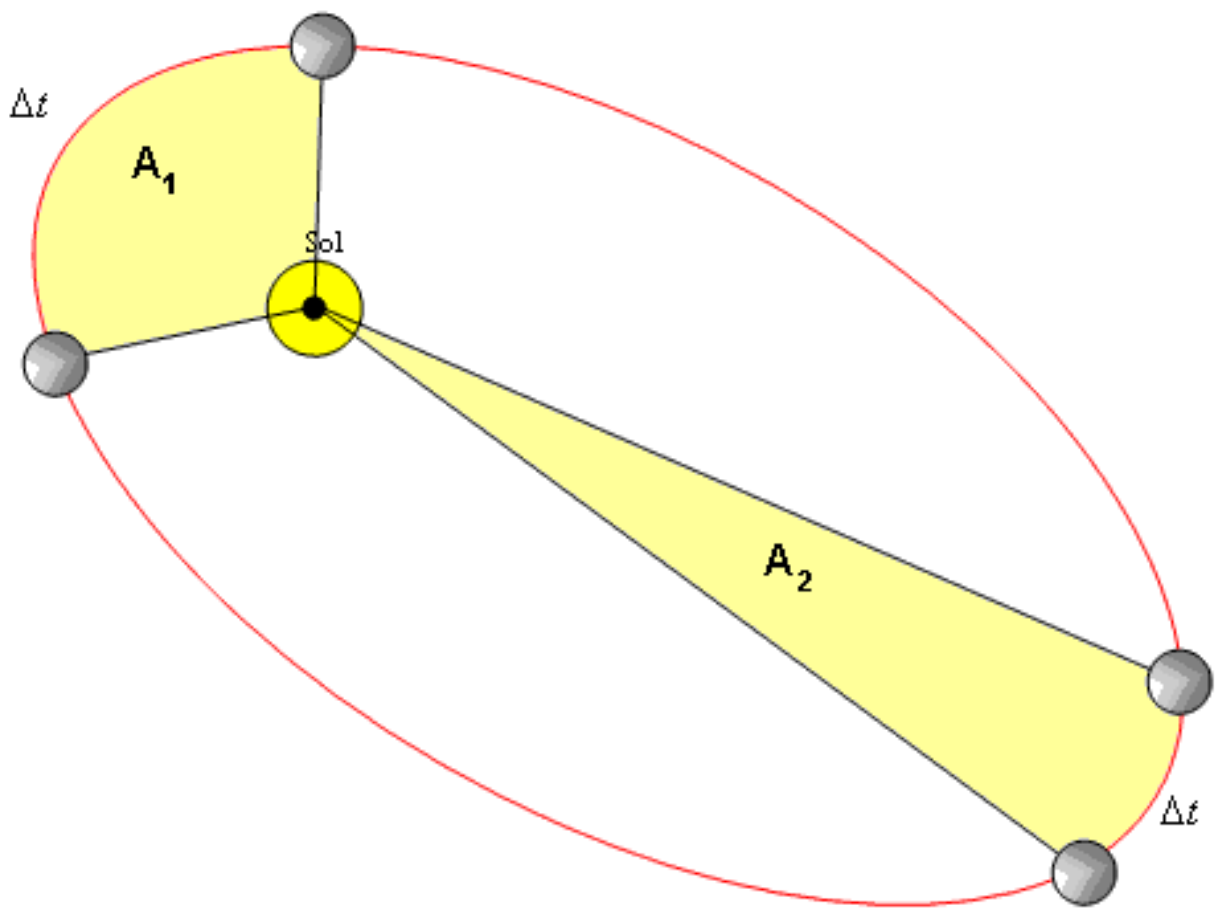

Figura 7 - Segunda lei de Kepler. A lei das áreas. Em seu movimento elíptico ao redor do Sol, o planeta percorre áreas iguais $\left(\mathrm{A}_{1}=\mathrm{A}_{2}\right)$ em tempos iguais $(\Delta t)$.

Essas duas leis keplerianas foram o resultado de um processo extremamente complexo, que foge ao propósito deste texto apresentar ou discutir. Mas o que é importante é sublinhar que essas leis são descritivas e que procuram representar as regularidades detectadas através das informações postas pelas observações dos corpos celestes. Essas duas leis, assim como a terceira, sobre a qual foi dito algo mais acima, são explicadas, segundo Kepler, pela ação física, uma espécie de força magnética, exercida pelo Sol nos planetas. Mas, para Kepler sustentar que é esta ação solar a responsável pelo comportamento dos planetas descrito nas leis, foi necessário que ele descrevesse como essa ação funciona. É aí que temos a função do termo moles.

O termo moles adquire função quando considerado no conjunto de sete axiomas propostos por Kepler na introdução à Astronomia nova para a elaboração da sua "verdadeira teoria da gravidade", como ele denomina. Para Kepler, a ação entre os corpos celestes obedece a relações físicas que implicam na atração dos corpos entre si, de modo a termos uma uniformidade no tratamento das relações entre corpos celestes. Como expressa Simon:

Isso foi acompanhado por um passo importante, pois permitiu aos corpos celestes aparecerem como objetos físicos, tendo as mesmas texturas e 
obedecendo às mesmas leis, compostos de elementos análogos àqueles que se encontram sobre a Terra ${ }^{21}$.

A utilização de moles aparece no quinto axioma, tal como escreve Kepler no original em latim:

Si duo lapides in aliquo loco mundi collocarentur propinqui invicem, extra orbem virtutis tertii cognati corporis; illi lapides ad similitudinem duorum Magneticorum corporum coirent loco intermedio, quilibet accedens ad alterum tanto intervallo, quanta est alterius moles in comparatione ${ }^{22}$.

Que traduzo para o português como:

Se duas pedras forem colocadas num lugar do mundo próximas uma da outra, fora da influência de algum corpo de valor cognato, essas pedras, de modo semelhante a dois corpos magnéticos, podem vir a unir-se em algum lugar intermediário, cada uma aproximando-se da outra por um intervalo proporcional à massa [moles] da outra.

Agora, apresento as traduções inglesa e francesa. $\mathrm{Na}$ edição inglesa, a tradução feita por Willian Donahue é:

If two stones were set near one another in some place in the world outside the sphere of influence of a third kindred body, these stones, like two magnetic bodies, would come together in an intermediate place, each approaching the other by an interval proportional to the bulk [moles] of the other ${ }^{23}$.

Notem que o tradutor utiliza bulk (volume, capacidade, grandeza, massa etc.), mas sem especificar exatamente o seu significado. Quanto à francesa, o tradutor, Jean Peyroux, optou por:

Si deux pierres mutuellement rapprochées étaient placées en un certain lieu du monde, en dehors de l'orbe de vertu d'un troisième corps parent, ces pierres iraient ensemble en un lieu intermédiaire selon la similitude des deux corps magnétiques, celle que l'on veut s'avançant vers l'autre d'un intervalle aussi grand que la masse de l'autre est grande en comparaison ${ }^{24}$.

21 SIMON, G. Kepler, astronome astrologue, Paris: Gallimard, 1979, p. 337.

22 KEPLER, J. Astronomia nova. In: CASPAR, M. \& VON DICK, W. (Ed.). Gesammelte Werke, v. 3. Munich: C. H. Beck'sche Verlagsbuchhandlung, 1937, p. 25-26.

23 KEPLER, J. New Astronomy. Trad. W. H. Donahue. Cambridge: Cambridge University Press, 1992b, p. 55.

24 KEPLER, J. Astronomie nouvelle. Trad. Jean Peyroux. Paris: Librairie A. Blanchard, 1979 , p. XXIII. 
$\mathrm{Na}$ tradução francesa, a utilização de massa é direta. Assim, as traduções inglesa e francesa, tal como entendo, estão traduzindo corretamente o termo moles. Contudo, sua utilização merece uma elucidação.

O problema da tradução de moles está em: qual a justificação para traduzi-lo como massa? Existem razões que se ligam ao modo pelo qual Kepler estava entendendo a atração entre os corpos celestes.

Penso que, para entender como moles opera dentro do conjunto de axiomas na introdução à Astronomia nova, é preciso relacioná-lo com outros conceitos, especificamente com gravitas e inertia. Acerca do primeiro, escreve Kepler:

Omnis substantia corpórea, quatenus corpórea, apta nata est quiescere omini loco, in quo solitaria ponitur, extra orbem virturis cognati corporis ${ }^{25}$.

Que traduzo:

Toda substância enquanto corpórea nasceu de modo a encontrar-se em repouso em todo lugar em que foi isoladamente colocada, fora da esfera de um corpo semelhante (cognato).

E, o segundo axioma:

Gravitas est afectio corporea, mutua inter cognata corporea ad unitionem seu conjunctionem (quo rereum ordine est et facultas magnetica) ut multo magis terra trahat lapidem, quam lápis petit terram ${ }^{26}$.

Com a seguinte tradução:

A gravidade é uma disposição corpórea mútua entre corpos cognatos (semelhantes) para uni-los conjuntamente; assim, a Terra atrai uma pedra muito mais do que a pedra atrai da Terra.

Kepler não está usando inertia na introdução à Astronomia nova. Contudo, pode-se entender a importância de inertia quando consideramos o que é posto no Epitome da astronomia copernicana, quando Kepler escreve:

Mesmo que um globo celeste não seja pesado do mesmo modo que entendemos que uma pedra sobre a Terra é dita ser pesada, [...]; todavia, por razões materiais, ele tem uma potência natural, ou capacidade de passar de lugar para lugar, e tem uma inércia [inertia] natural para permanecer em repouso em todo lugar que é colocado sozinho. E, portanto, como ele pode ser movido fora de sua posição e repouso, é necessário que haja algum poder que

25 KEPLER, J. Astronomia nova. In: CASPAR, M. \& VON DICK, W. (Ed.). Gesammelte Werke, v. 3. Munich: C. H. Beck'sche Verlagsbuchhandlung, 1937, p. 25-26.

26 KEPLER, J. Astronomia nova. In: CASPAR, M. \& VON DICK, W. (Ed.). Gesammelte Werke, v. 3. Munich: C. H. Beck'sche Verlagsbuchhandlung, 1937, p. 25-26. 
seja mais vasto que sua matéria e seu corpo nu, e o qual possa retirá-lo de sua inércia natural ${ }^{27}$.

Ou em outra passagem que diz que:

Se a matéria dos corpos celestes não fosse dotada de inércia [inertia], alguma coisa similar ao peso, nenhuma força seria necessária para mover o globo planetário; uma pequeníssima força seria suficiente para dar a ele uma velocidade infinita. Entretanto, como os períodos das revoluções planetárias têm tempos definidos, algumas vezes grandes e outras vezes pequenos, tornase claro que a matéria deve ter uma inércia que produz essas diferenças ${ }^{28}$.

Bem, o significado de gravitas na língua latina é o de substantivo feminino, com as acepções de pesadume, peso, gravidez, prenhes, que é derivado do adjetivo gravis, significando pesado, grave, carregado, grávida, prenhe. O sentido de inertia, um substantivo feminino, é ignorância, incapacidade, inaptidão, ociosidade etc., que é derivado do adjetivo iners, que significa incapaz, improdutivo, ocioso, imóvel, inativo etc. Finalmente, o substantivo feminino moles indica massa, volume, corpo, massa de matéria, obra de alvenaria, máquinas de guerra, peso etc.

O primeiro axioma contido na introdução à Astronomia nova, quando considerado em junção com a primeira passagem do Epitome na página 296, determina a inércia natural de um planeta qualquer. Inércia, para Kepler, significa "manter-se em repouso", "manter-se em seu estado original de repouso", que pode significar "resistir à ação exercida pela força solar central". Se um planeta não sofrer nenhuma ação, isto é, se ele permanecer sozinho em seu lugar, em repouso, ele manter-se-á nesse estado, assim, eternamente. Ademais, a inércia natural de um planeta indica que esse tem uma quantidade de matéria (moles, isto é, massa) suficiente para resistir à força completa do Sol.

O segundo axioma, também em conjunto com a segunda passagem do Epitome, na página 297, apresenta a espécie de ação que pode levar o planeta a sair de seu estado de inércia. Para que ele se mova, faz-se necessária a ação de uma força que seja superior à sua quantidade de matéria [uma força superior à emitida pelo seu corpo - sua massa], que lhe retira de sua inércia natural. Kepler utiliza o sentido de grave (pesado) significando "atração", ou, poder que um corpo tem sobre um outro para retirá-lo de seu estado de repouso. Nota, também, que a gravidade é uma ação

27 KEPLER, J. Epitome astronomiae copernicanae. In: CASPAR. M. \& VON DICK, W. (Ed.). Gesammelte Werke, v. 7. Munich: C. H. Beck'sche Verlagsbuchhandlung, 1953, p. 296.

28 KEPLER, J. Epitome astronomiae copernicanae. In: CASPAR. M. \& VON DICK, W. (Ed.). Gesammelte Werke, v. 7. Munich: C. H. Beck'sche Verlagsbuchhandlung, 1953, p. 297. 
mútua, o que pode significar que cada corpo, e não somente o Sol, exerce ação (força) na relação. Assim, a relação pode ser expressa da seguinte maneira: dois objetos, duas pedras, por exemplo, podem se unir mediante a relação dada pela proporcionalidade de suas massas, determinada pela sua inércia natural.

Portanto, ocorre com toda essa investigação de Kepler a procura de explicação das ações físicas, sugeridas pelas leis descritivas (variações entre distâncias, tempos e velocidades), através do uso de conceitos.

Deve ser ressaltado que esses conceitos, e outros dos quais não tratei, ainda não estão plenamente definidos (gravitas como peso; inertia idêntica a repouso ou resistência; moles podendo significar massa, mas não, ainda, a massa newtoniana), mas apontam para certa direção: a de explicar como se dá a relação física entre a atração do Sol nos planetas. Neste sentido, uma possível interpretação dos conceitos é a seguinte: moles, enquanto massa do corpo (não apenas o seu volume), mas a quantidade total da matéria de um corpo; gravitas como uma ação para a atração de corpos (relação entre as massas; talvez a diferença entre os pesos); inertia, como a tendência do corpo (massa) a resistir à massa superior de outro.

Finalizando, entendo, como apontei mais acima, que as traduções inglesa e francesa traduzem corretamente moles por massa; o que talvez seja importante é discutir a utilização de massa como tradução. O termo não está, acredito, deslocado de um conjunto maior de termos, como gravitas e inertia, de modo que se torna fundamental entender como esses conceitos relacionam-se para a compreensão da teoria da gravidade desenvolvida por Kepler em seus escritos.

\section{Conclusão}

A intenção deste texto foi discutir brevemente as possibilidades de tradução de termos científicos, no caso, analisou-se três termos importantes da obra astronômica e cosmológica de Kepler. A proposta que apresento é a de traduzir commoditates por "justas proporções matemáticas", distinta das traduções inglesa, francesa e espanhola, que entendem o termo como "vantagens matemáticas". Traduzo o termo harmoniae por "harmonia", distinguindo da tradução francesa que traduz por "um acordo" e da espanhola, que utiliza "consonância". E o temo moles, que traduzo por massa, em concordância com as traduções inglesa e francesa. Mas o mais importante, penso, é traduzir os conceitos dentro do contexto em que eles são utilizados, de maneira a traduzi-los com vistas à compreensão do trabalho desenvolvido por Kepler em astronomia e cosmologia. 
Agradeço aos professores Sílvio Rosa Filho e Thomaz Massadi Kawauche tanto pelo convite para a conferência que apresentei nos encontros do LELPraT como pela publicação deste artigo, fruto da conferência apresentada. Faço um agradecimento especial à Daniela Cristina Gonçalves pela revisão do texto original e pelas sugestões dadas para a sua melhoria.

\section{Referências bibliográficas}

CASPAR, Max. Kepler. New York: Dover Publications, 1959.

COPÉRNICO, Nicolau. As revoluções dos orbes celestes. Lisboa: Fundação Calouste Gulbenkian, 1984.

COSTABEL, Pierre. "Kepler and the Copernican Model". Vistas in Astronomy, 18, p. 217-222, 1975.

HANSON, Norton. Constelaciones y conjeturas. Madrid: Alianza Universidad, 1985.

KEPLER, Johannes. Astronomia nova. In: CASPAR, M. \& VON DICK, W. (Ed.).

Gesammelte Werke, v. 3. Munich: C. H. Beck'sche Verlagsbuchhandlung, 1937. . Mysterium cosmographicum. In: CASPAR. M. \& VON DICK, W. (Ed.). Gesammelte Werke, v. 1. Munich: C. H. Beck'sche Verlagsbuchhandlung, 1938. p. 1-80.

Harmonice mundi. In: CASPAR. M. \& VON DICK, W. (Ed.). Gesammelte Werke, v. 6. Munich: C. H. Beck'sche Verlagsbuchhandlung, 1940.

. Epitome astronomiae copernicanae. In: CASPAR. M. \& VON DICK, W. (Ed.). Gesammelte Werke, v. 7. Munich: C. H. Beck'sche Verlagsbuchhandlung, 1953. 1977.

L'harmonie du monde. Trad. Jean Peyroux. Paris: Librairie A. Blanchard, . Astronomie nouvelle. Trad. Jean Peyroux. Paris: Librairie A. Blanchard, 1979.

Mysterium cosmographicum. Trad. A. M. Ducan. New York: Abaris Books, 1981.

Le secret du monde. Trad. e notas de Alain Segonds. Paris: Gallimard, 1984.

El secreto del universo. Trad. Eloy R.García. Madrid: Alianza Editorial, 1992a.

New Astronomy. Trad. W. H. Donahue. Cambridge: Cambridge University Press, $1992 b$.

KOYRÉ, Alexander. La révolution astronomique. Paris: Hermann, 1961.

MOURÃO, Ronaldo Rogério. Kepler, a descoberta das leis do movimento planetário.

Rio de Janeiro: Odysseus, 2003.

SIMON, Gérard. Kepler, astronome astrologue. Paris: Gallimard, 1979.

STEPHENSON, Bruce. Kepler's Physical Astronomy. New York: Springer Verlag, 1987. 


\section{Translation and Scientificity}

Abstract. Intended in this article to present some translation possibilities of three concepts used for J. Kepler in the elaboration its three laws of planetary motions, this is, commoditates, harmonia and moles. The article still treats of importance of conjugate the translation of concepts in the scope employed by Kepler during the elaboration process its laws. Therefore, the proposed translations to the three concepts are collated with of English, French and Spanish translations.

Keywords: Kepler, laws, translation, astronomy, cosmology. 